\title{
A note on contributions
}

Chapters 1-5 are the result of teamwork between EFTEC (Economics for the Environment Consultancy) and CSERGE (Centre for Social and Economic Research on the Global Environment) on a project funded by the Charities Aid Foundation. Contributing authors are Vivien Foster, Susana Mourato, Ece Özdemiroğlu, Steve Dobson, David Pearce and Tannis Hett.

Chapters 6-8 have been prepared by Vivien Foster under an award from the UK Economic and Social Research Council (ESRC). Vivien wishes to thank the ESRC for their support.

Chapters 9-10 were drafted by David Pearce, Vivien Foster and Susana Mourato. 